\title{
Efeito da suplementação com Blocos Multinutricionais sobre o desempenho e características de carcaça de ovinos e caprinos na Caatinga
}

\author{
[Effect of supplementation with Multinutrient Blocks on the performance and carcass \\ characteristics of sheep and goats in Caatinga]
}

\author{
M.A. Cordão ${ }^{1}$, M.F. Cezar ${ }^{2}$, M.G.G. Cunha ${ }^{3}$, W.H. Sousa ${ }^{3}$, J.M. Pereira Filho ${ }^{3}$, B.S. Lins ${ }^{4}$, \\ J.B.A. Menezes ${ }^{4}$, G.H. Nóbrega ${ }^{5}$ \\ ${ }^{1}$ Aluna de pós-graduação - UFCG - Patos, PB \\ ${ }^{2}$ UFCG - Patos, PB \\ ${ }^{3} \mathrm{EMEPA}-\mathrm{PB}$ \\ ${ }^{4}$ Aluno de graduação - UFCG - Patos, PB \\ ${ }^{5}$ Médica veterinária - Prefeitura Municipal de Gravatá, PE
}

\section{RESUMO}

Este trabalho avaliou o desempenho e as características de carcaça e não constituintes de carcaça de ovinos e caprinos em área de caatinga, suplementados com blocos multinutricionais (BMs). O trabalho foi desenvolvido na Estação Experimental da EMEPA em Soledade, Paraíba, Brasil, de acordo com um delineamento inteiramente ao acaso com 3x2 tratamentos fatoriais (3 níveis de suplementação de animais em pastejo na caatinga: S1 = sal mineral; S2 = BMs; e S3 = BMs + feno de capim buffel, e duas espécies de animais: ovinos e caprinos) e dez repetições de um animal. Os ganhos de peso se mostraram mais elevados para os animais suplementados com sal mineral. Os ovinos obtiveram ganho de peso médio diário (GPMD=104,83g) e ganho de peso total $(\mathrm{GPT}=11,32 \mathrm{~kg})$ superior aos caprinos (GPMD=92,90g e GPT=10,04kg). O peso vivo ao abate (PVA), o peso da carcaça quente (PCQ) e fria (PCF) foram superiores para os animais suplementados com sal mineral. O peso corporal vazio (PCV), rendimento biológico (RB), rendimento comercial (RC), rendimento verdadeiro (RV) e perda por resfriamento (PPR) não foram afetados pelos níveis de suplementação. O PVA dos ovinos (PVA=27,62kg) superou o dos caprinos (PVA= 25,34kg), e o RB, RC e RV dos caprinos foram superiores aos dos ovinos. Houve efeito significativo $(\mathrm{P}<0,05)$ dos níveis de suplementação no rendimento $(\%)$ do peso do trato gastrintestinal cheio (TGIc), peso do trato gastrintestinal vazio (TGIv), fígado, coração e rins. A suplementação com blocos multinutricionais ou em conjunto com feno de baixa qualidade, para ovinos e caprinos sob pastejo direto na caatinga, com forragem em quantidade e qualidade satisfatórias, não resulta em ganhos produtivos significativos.

Palavras-chave: manejo extensivo, pequenos ruminantes, suplementação

\begin{abstract}
This study evaluated the performance and carcass characteristics and non carcass constituents of sheep and goats foraging in the caatinga rangeland, supplemented with multi-nutrients blocks (MBs). The experiment was carried out at EMEPA Experimental Station in Soledade-PB, Brazil, according to a completely randomized design with $3 \times 2$ factorial treatments (three levels of supplementation of animal foraging in the caatinga rangeland: $S 1=$ mineral salt; $S 2=M B s$, and S3 = MBs + buffel grass hay, and 2 species: sheep and goat) and 10 replications of one animal. Mean daily and total weight gain (MDWG and TWG) showed to be higher for animals supplemented with salt, and it was higher for sheep ( $M D W G=104.83 \mathrm{~g}$ and $T W G=11$. $32 \mathrm{~kg}$ ) than for goats ( $M D W G=92.90 \mathrm{~g}$ and $T W G=10.04 \mathrm{~kg}$ ). Slaughtering weight (SW), hot carcass (HCW) and cold carcass (CCW) weights were higher for animals supplemented with mineral salt. Empty body weight (EBW), biological yield (BY), commercial yield (CY),
\end{abstract}

Recebido em 26 de agosto de 2013

Aceito em 2 de julho de 2014

E-mail: maizacordao@hotmail.com

Apoio financeiro: $\mathrm{CNPq}$ 
true yield (TY) and loss by cooling (LC) were not affected by supplementation levels. Sheep SW=27.62 $\mathrm{kg}$ was higher than goat $S W=25.34$, while $B R, C R$ and VR were higher for goats. There were significant $(P<0.05)$ effects of supplementation levels on yield (\%) of weight of the full gastrointestinal tract (IGTc), weight of the empty gastrointestinal tract (IGTV), liver, heart and kidneys. Supplementation with multinutrient blocks alone or in conjunction with low quality hay for sheep and goats grazing in the caatinga rangeland with satisfactory forage quantity and quality does not result in significant productivity gains.

Keywords: extensive management, small ruminants, supplementation

\section{INTRODUÇÃO}

A criação de ovinos e caprinos no Nordeste do Brasil é uma atividade em expansão e bastante aceitável pelos produtores, por ser de fácil implantação e exploração, se destacando como uma atividade de grande relevância socioeconômica. A produção desses animais na região ocorre, em sua grande maioria, de modo extensivo e muito dependente da vegetação da caatinga.

Essa vegetação apresenta grande número de espécies, entre as quais se destacam plantas de interesse forrageiro (Ydoyaga-Santana et al., 2011), chegando a participar em até $90 \%$ da dieta de ovinos e caprinos (Gonzaga Neto et al., 2001). O pasto herbáceo nativo é adequado para a terminação de ruminantes na estação chuvosa; porém, na época seca, sua qualidade e quantidade comprometem o desempenho animal (Gonzaga Neto et al., 2001). Segundo Ben Salem (2010), o grande entrave desse sistema de produção é que, na época de estiagem, os nutrientes desses recursos alimentares são tão baixos e desequilibrados que há necessidade de suplementos para os animais.

Várias pesquisas vêm sendo realizadas no intuito de encontrar formas e alimentos para suplementação dos animais na caatinga. O capim buffel (Cenchrus ciliaris L.) constitui uma boa fonte suplementar; bastante utilizado pelos produtores, por sua adaptabilidade e resistência às condições ambientais da região (Andrade et al., 2010). Uma alternativa a ser estudada é o uso de blocos multinutricionais, ainda não estudados no bioma Caatinga, mas avaliados em regiões semiáridas (Araújo-Febres et al., 1997) em bovinos; (Martínez-Martínez et al., 2012) em ovinos; e (Ben Salem e Nefzaoui, 2003) em caprinos e ovinos, principalmente em animais em pastejo no período de estiagem.
Os blocos multinutricionais, constituídos em sua maioria de proteína, energia e minerais, são uma mistura solidificada não convencional, cujos ingredientes básicos são melaço, ureia, minerais e vitaminas, dentre outros (Ben Salem e Nefzaoui, 2003). Além disso, possuem características nutritivas necessárias para os animais durante os períodos críticos de escassez de forragem (Martínez-Martínez et al., 2012), que consequentemente ajuda produzir animais de maior desempenho e carcaça de melhor qualidade, principalmente em termos de rendimento e composição tecidual, gerando qualidade do produto final, ou seja, a carne (Oliveira et al., 2008).

Visando à necessidade de melhorar o desempenho e a produção de carne de ovinos e caprinos na região semiárida, o objetivo da realização deste trabalho foi avaliar o desempenho e as características de carcaça e não constituintes de carcaça de ovinos e caprinos, em área de caatinga, suplementados com blocos multinutricionais (BMs).

\section{MATERIAL E MÉTODOS}

Este trabalho foi desenvolvido entre os meses de dezembro de 2011 a maio de 2012, na Estação Experimental de Pendência, pertencente à EMEPA-PB (Empresa de Pesquisa Agropecuária da Paraíba S.A.), localizada na mesorregião do Agreste Paraibano, na microrregião do Curimataú ocidental, no município de Soledade, Paraíba.

O clima, segundo a classificação de Koppen, é do tipo semiárido quente - Bsh, com chuvas concentradas nos meses de janeiro a junho (EMEPA-PB, 2012). A média de temperatura na área experimental pela manhã teve máxima de $23,3^{\circ} \mathrm{C}$ e mínima de $22,3^{\circ} \mathrm{C}$, e no período da tarde, máxima de $33,5^{\circ} \mathrm{C}$ e mínima de $32,7^{\circ} \mathrm{C}$. A precipitação pluvial nesse ano foi, em média, de $178,9 \mathrm{~mm} / \mathrm{ano}$. 
O experimento foi desenvolvido em uma área de caatinga em repouso havia quatro anos. A área foi dividida em três piquetes de 12,5ha, determinando três tratamentos experimentais. Antes da instalação do experimento (dezembro de 2011), no meio (janeiro) e no final (março de 2012), foram feitas avaliações da disponibilidade de matéria seca dos estratos herbáceo e arbustivo-arbóreo, realizadas através da metodologia de Araújo Filho et al. (1987). A partir desses resultados, foi estimada a disponibilidade de matéria seca por hectare, expressos em $\mathrm{kg} / \mathrm{ha}$ e por $\mathrm{kg}$ de PV animal (Tab. 1). Logo após as coletas, todo o material foi levado ao laboratório de análises de alimentos na UFCG/Patos-PB, para determinação da composição química (Tab. 2) realizada através da metodologia descrita por Silva e Queiroz (2002).

Tabela 1. Disponibilidade de matéria seca do estrato herbáceo e arbustivo-arbóreo nas áreas de caatinga (Caat.) pastejada por ovinos e caprinos suplementados com blocos multinutricionais (BMs)

\begin{tabular}{ccccccccc}
\hline \multirow{2}{*}{ Suplemetação } & \multicolumn{4}{c}{ kg de MS/ha } & \multicolumn{5}{c}{ kg de MS/kg de PV animal } \\
\cline { 2 - 8 } & Arbóreas & Gramíneas & Dicotiledôneas & Total & Arbóreas & Gramíneas & Dicotiledôneas & Total \\
\hline Caat + sal & 121,35 & 138,22 & 803,86 & 1063,4 & 0,264 & 0,323 & 1,875 & 2,463 \\
mineral & 83,97 & 124,75 & 548,46 & 757,1 & 0,192 & 0,318 & 1,301 & 1,812 \\
Caat + BMs & 123,82 & 606,68 & 817,3 & 0,207 & 0,300 & 1,225 & 1,998 \\
$\begin{array}{c}\text { Caat + BMs + } \\
\text { feno de buffel }\end{array}$ & 86,89 & 120 & \\
\hline
\end{tabular}

Os blocos multinutricionais foram confeccionados na EMEPA-PB, utilizando-se os seguintes ingredientes: $25 \%$ de melaço, $5 \%$ de ureia pecuária, $24 \%$ de milho triturado, $24 \%$ de farelo de soja, $5 \%$ de sal comum, $7 \%$ de sal mineral e $10 \%$ de cal hidratada. Os ingredientes dos blocos, após serem pesados em balança digital, foram misturados em uma betoneira, colocados em prensa hidráulica de 7 toneladas por 1 a 2 minutos, em seguida retirados da prensa e mantidos em temperatura ambiente por 48 horas antes do consumo. O sal mineral utilizado foi adquirido no comércio local. O feno de capim buffel foi confeccionado na estação da EMEPA$\mathrm{PB}$, triturado em peneira de $5 \mathrm{~mm}$ em máquina forrageira, cuja composição química está apresentada na Tab. 2.

Tabela 2. Composição química (g/kg)* da vegetação disponível nas áreas de caatinga pastejadas por ovinos e caprinos suplementados com blocos multinutricionais, dos blocos multinutricionais (BMs) e do feno de buffel

\begin{tabular}{cccccccccc}
\hline \multirow{2}{*}{ Composição } & \multicolumn{1}{c}{ Componente Vegetal } & \multicolumn{3}{c}{ Suplemento } \\
\cline { 2 - 10 } & Gramínea & Dicotiledônea & Pereiro & Catingueira & Marmeleiro & Mofumbo & Jurema preta & BMs & $\begin{array}{c}\text { Feno de } \\
\text { buffel }\end{array}$ \\
\hline MS & 797,0 & 747,9 & 381,5 & 512,82 & 508,8 & 248,5 & 614 & 909,3 & 943,8 \\
MM $^{2}$ & 61,23 & 41,63 & 77,60 & 45,26 & 58,06 & 80,2 & 32,93 & 708,1 & 69,5 \\
MO $^{2}$ & 938,7 & 958,3 & 922,4 & 954,7 & 941,9 & 919,8 & 967,0 & 291,9 & 930,5 \\
PB $^{2}$ & 22,93 & 43,63 & 103,8 & 105,9 & 141,4 & 148,5 & 91,6 & 285,9 & 39,7 \\
FDN $^{2}$ & 775,0 & 759,9 & 387,5 & 390,1 & 559,5 & 335,3 & 554,53 & 266,2 & 702,3 \\
FDA $^{2}$ & 567,5 & 610,2 & 289,0 & 304,0 & 430,3 & 250,6 & 430,5 & 86,0 & 389,7 \\
\hline
\end{tabular}

*MS = Matéria Seca ${ }^{1} \mathrm{~g} / \mathrm{kg}$ MN; ${ }^{2}$ (g/kgMS) MM = Matéria Mineral; MO = Matéria Orgânica; PB = Proteína Bruta; FDN = Fibra em detergente neutro; FDA = Fibra em detergente ácido; Pereiro (Aspidosperma pyrifolium Mart.); Catingueira (Poincianella pyramidalis Tul. L.P. Queiroz); Marmeleiro (Croton blanchetianus Baill); Mofumbo (Combretum leprosum Mart); Jurema preta (Mimmosa tenuiflora (Willd.) Poiret).

A avaliação do desempenho dos animais teve duração de 108 dias, precedidos de 14 dias de adaptação ao manejo. Foram utilizados 60 animais, sendo 30 ovinos e 30 caprinos sem raça definida (SRD), machos inteiros, com média de 120 dias de idade e peso vivo médio inicial de $18,63 \pm 1,93 \mathrm{~kg}$. Os animais, após serem identificados, foram mantidos em regime extensivo em uma área de caatinga, submetidos a três tipos de suplementação: caatinga + sal mineral; caatinga + BMs; caatinga + BMs + feno de capim buffel. Cada piquete continha abrigo com acesso livre à água, ao sal mineral, BMs e feno de buffel, de acordo com os tratamentos, os 
quais eram fornecidos aos animais ad libitum, em cocho suspenso em local prefixado. Os animais foram pesados a cada 14 dias para avaliação do ganho em peso, assim como foi realizada estimativa de consumo do sal mineral, dos BMs e do feno de capim buffel, obtida pela diferença entre o oferecido e as sobras.

Ao final do período experimental de campo, após jejum hídrico e alimentar de 18 horas, os animais foram pesados (PVA) e logo após abatidos, sendo atordoados, suspensos pelas patas traseiras, sangrados pela veia jugular e artéria carótida, esfolados e eviscerados. $\mathrm{O}$ trato gastrintestinal (TGI), bexiga e vesícula biliar cheios foram pesados, esvaziados e limpos para nova pesagem para obter o peso de corpo vazio (PCV). Os não constituintes da carcaça considerados comestíveis foram coletados e pesados para cálculos de proporção em relação ao PCV.

As carcaças foram pesadas, obtendo-se o peso da carcaça quente (PCQ). Em seguida foram acondicionadas em sacos plásticos, transportadas para uma câmera fria a $4^{\circ} \mathrm{C}$, onde permaneceram por um período de $24 \mathrm{~h}$ para, em seguida, serem pesadas para a obtenção do peso da carcaça fria (PCF). Foi ainda obtido o rendimento verdadeiro (PCQ/PVA $x$ 100), o rendimento biológico (PCQ/PCV x 100), o rendimento comercial da carcaça (PCF/PVA x 100) e perda de peso da carcaça pelo resfriamento $(\mathrm{PPR}=\mathrm{PCQ}$ PCF/PCQ x 100), de acordo com Cezar e Sousa (2007).

O delineamento experimental utilizado foi o inteiramente casualizado (DIC), num esquema fatorial 3x2 (três tipos de suplementação: caatinga + sal mineral; caatinga + BMs e caatinga + BMs + feno de buffel; e duas espécies de animais: ovinos e caprinos) e 10 repetições. Os dados foram submetidos à análise de variância, e as médias, comparadas pelo teste Tukey a 5\% de probabilidade, utilizando o programa SAS (Statistical..., 2003).

\section{RESULTADOS E DISCUSSÃO}

A média da estimativa de consumo diário foi de 15,$34 ; 48,71 ; 77,36$ e $50,15 \mathrm{~g} / \mathrm{an}$, e o consumo total, de 37,49; 109,88; 167,26 e 108,42kg, respectivamente para os animais suplementados com sal mineral, BMs, BMs e feno de buffel.
O consumo de MS de blocos nos animais suplementados apenas com BMs foi de 48,71g/an/dia, valor considerado abaixo do limite indicado por Makkar et al. (2007), que relatam um consumo diário de blocos por animal variando de 60 a $125 \mathrm{~g}$ para ovinos e caprinos em geral. Isso provavelmente se deve à época em que o estudo foi realizado, em que havia abundância de forragem, com disponibilidade de matéria seca variando de 1,812 a $2,463 \mathrm{~kg} / \mathrm{kg}$ de PV animal (Tab. 1), na qual havia presença de forrageiras nativas com índices de proteína bruta entre 91,6 a 148,5g/kg MS (Tab. 2), valor superior ao mínimo necessário ao funcionamento das atividades dos microrganismos do rúmem (Van Soest, 1994).

Outro aspecto a ser considerado é a presença de gramíneas e dicotiledôneas herbáceas com elevado valor forrageiro, permitindo aos animais consumi-las e transformá-las em produtos como carne e leite (Pereira Filho e Bakke, 2010). Estes resultados vêm confirmar a teoria de MartínezMartínez et al. (2012), que relataram que o consumo de blocos tem maior impacto quando as forrageiras disponíveis no campo são de baixa qualidade e contêm pouca energia.

Os animais suplementados com BMs + feno de buffel obtiveram consumo de blocos de $77,36 \mathrm{~g} / \mathrm{an} / \mathrm{dia}$, superando numericamente os suplementados apenas com BMs, com consumo de $48,77 \mathrm{~g} / \mathrm{an} / \mathrm{dia}$. Isso deve ter ocorrido pelo fato de os animais terem à sua disposição, além dos BMs, uma fonte de fibra (feno de buffel) próxima aos saleiros, induzindo os animais a permanecerem por mais tempo no aprisco, acontecendo assim maior busca pela suplementação, para suprirem sua carência alimentar, já que o feno de capim buffel utilizado se encontrava em baixa qualidade, com percentual de proteína bruta de 39,7g/kg MS (Tab. 2). Nesse contexto, Kawas et al. (2010) reportaram que animais consumindo forragens de baixa qualidade, geralmente aumentam a ingestão dos blocos.

Não houve interação entre as suplementações e as espécies animais para PI, GPMD, GPT, GPM e GPC. Os ganhos de peso foram mais elevados para os animais suplementados com sal mineral, sendo os com BMs equivalentes, tanto aos animais suplementados com sal mineral quanto aos suplementados com BMs e feno de buffel (Tab. 3). 
Tabela 3. Ganhos de peso de ovinos e caprinos suplementados com blocos multinutricionais em pastejo na caatinga (Caat)

\begin{tabular}{|c|c|c|c|c|c|c|c|}
\hline \multirow[b]{2}{*}{ Variáveis* } & \multicolumn{3}{|c|}{ Tipos de suplementação } & \multirow[b]{2}{*}{$\mathrm{P}^{* *}$} & \multicolumn{2}{|c|}{ Espécies } & \multirow[b]{2}{*}{$P$} \\
\hline & $\begin{array}{c}\text { Caat + sal } \\
\text { mineral }\end{array}$ & $\begin{array}{l}\text { Caat + } \\
\text { BMs }\end{array}$ & $\begin{array}{l}\text { Caat + BMs + } \\
\text { feno de Buffel }\end{array}$ & & Ovinos & Caprinos & \\
\hline PI (kg) & $18,50 \mathrm{~A}$ & $18,45 \mathrm{~A}$ & $18,95 \mathrm{~A}$ & 0,678 & $19,03 a$ & $18,23 a$ & 0,12 \\
\hline GPMD (g) & $111,20 \mathrm{~A}$ & $96,50 \mathrm{AB}$ & $88,90 \mathrm{~B}$ & 0,007 & $104,83 a$ & $92,90 b$ & 0,04 \\
\hline GPT (kg) & $12,00 \mathrm{~A}$ & $10,42 \mathrm{AB}$ & $9,60 \mathrm{~B}$ & 0,008 & $11,32 \mathrm{a}$ & $10,04 b$ & 0,04 \\
\hline GPM $\left(g / \mathrm{kg}^{0,75}\right)$ & $10,07 \mathrm{~A}$ & $8,93 \mathrm{AB}$ & $8,23 B$ & 0,005 & $9,43 a$ & $8,72 \mathrm{a}$ & 0,11 \\
\hline GPC (g) & $0,653 \mathrm{~A}$ & $0,567 \mathrm{AB}$ & $0,510 \mathrm{~B}$ & 0,005 & 0,598a & $0,555 a$ & 0,22 \\
\hline GPC (\%) & $65,38 \mathrm{~A}$ & $56,75 \mathrm{AB}$ & $51,00 \mathrm{~B}$ & 0,005 & 59,86a & $55,55 a$ & 0,22 \\
\hline
\end{tabular}

*PI = Peso inicial; GPMD = Ganho de peso médio diário; GPT = Ganho de peso total; GPM = Ganho de peso metabólico; GPC = Ganho de peso corporal (g e \%); **Letras diferentes, maiúsculas para tipos de suplementação e minúsculas para espécies, na mesma linha, significam diferenças estatísticas entre os tratamentos pelo teste Tukey a $5 \%$ de probabilidade.

O inferior ganho de peso médio e total para os animais suplementados com BMs + feno de buffel em relação aos com sal mineral deve estar relacionado à preferência destes em ficar por mais tempo no aprisco, pela conveniência de encontrar uma fonte de fibra (feno de buffel), reduzindo o consumo das forrageiras da caatinga e, consequentemente, diminuiu o ganho de peso dos animais. Tal fato se constitui no fenômeno chamado de efeito substitutivo ou de substituição, onde se observam efeitos indesejáveis de suplementação, com uma redução no consumo de forragem, em função da suplementação fornecida (Prohmann et al., 2004).

Os ovinos obtiveram ganho de peso médio diário e ganho de peso total superior aos caprinos $(\mathrm{P}<0,05)$ (Tab. 3). No geral, os pequenos ruminantes são os animais em que menos se observam efeitos de blocos multinutricionais, pois, segundo a Makkar et al. (2007), os efeitos positivos dos blocos são mais pronunciados em bovinos, seguidos de búfalos e, por fim, em ovinos e caprinos, respectivamente. No entanto, em termos percentuais de ganho de peso em função do peso corporal, as espécies obtiveram o mesmo ganho de peso.

O GPMD dos ovinos supera os resultados encontrados por Martínez-Martínez et al. (2012), em estudo com ovinos em sistema silvipastoril suplementados com BMs, quando observaram média de GPMD de 73,5g, assim como os resultados de Atti e Ben Salem (2008), estudando os efeitos dos blocos em ovinos Barbarine, que encontraram média de GPMD de 70,0g. Esse aspecto se deve provavelmente ao fato de que a formulação dos BMs desta pesquisa foi baseada apenas em concentrados, obtendo BMs de alto valor proteico $(285,9 \mathrm{~g} / \mathrm{kg} \mathrm{MS})$, baixos valores de FDN (266,2g/kg MS) e FDA (86g/kg MS) (Tab. 2), que favorecem uma boa absorção de nutrientes, diferentemente desses autores, cujas pesquisas se basearam em forrageiras; pois, de acordo com Atti e Ben Salem (2008), as respostas dos blocos multinutricionais dependem da composição dos ingredientes alimentares.

O peso vivo ao abate (PVA), peso da carcaça quente (PCQ) e peso da carcaça fria (PCF) foram superiores para os animais suplementados somente com sal mineral. $\mathrm{O}$ peso corporal vazio (PCV), rendimento biológico (RB), rendimento comercial (RC), rendimento verdadeiro $(\mathrm{RV})$ e perda por resfriamento (PPR) não diferiram estatisticamente $(P>0,05)$ entre as suplementações (Tab. 4).

O PVA superior nos animais suplementados com sal mineral se deve ao seu maior ganho de peso (Tab. 3) e, por conseguinte, maior PCQ $(12,25 \mathrm{~kg})$ e PCF $(11,88 \mathrm{~kg})$. O PCQ dos animais suplementados com BMs (10,95kg) e BMs + feno de buffel $(10,98 \mathrm{~kg})$ podem ser comparados aos encontrados por Oliveira et al. (2008) em caprinos SRD, em pastagem nativa raleada, suplementados com milho e soja, que observaram PCQ de 10,74kg. 
Efeito da suplementação...

Tabela 4. Características de carcaça de ovinos e caprinos suplementados com blocos multinutricionais em pastejo na caatinga (Caat)

\begin{tabular}{|c|c|c|c|c|c|c|c|}
\hline \multirow[b]{2}{*}{ Variáveis* } & \multicolumn{3}{|c|}{ Tipos de suplementação } & \multirow[b]{2}{*}{$\mathrm{P} * *$} & \multicolumn{2}{|c|}{ Espécies } & \multirow[b]{2}{*}{$\mathrm{P}$} \\
\hline & $\begin{array}{c}\text { Caat + Sal } \\
\text { mineral }\end{array}$ & $\begin{array}{c}\text { Caat + } \\
\text { BMs }\end{array}$ & $\begin{array}{l}\text { Caat + BMs + } \\
\text { feno de Buffel }\end{array}$ & & Ovinos & Caprinos & \\
\hline PVA (kg) & $27,94 \mathrm{~A}$ & $25,86 \mathrm{AB}$ & $25,64 \mathrm{~B}$ & 0,03 & $27,62 \mathrm{a}$ & $25,34 b$ & 0,004 \\
\hline PCQ (kg) & $12,25 \mathrm{~A}$ & $10,95 B$ & $10,98 \mathrm{AB}$ & 0,02 & $11,21 \mathrm{a}$ & $11,57 a$ & 0,402 \\
\hline PCF (kg) & $11,88 \mathrm{~A}$ & $10,43 B$ & $10,58 B$ & 0,01 & $10,78 a$ & $11,14 \mathrm{a}$ & 0,400 \\
\hline PCV (kg) & $24,29 \mathrm{~A}$ & $21,02 \mathrm{~A}$ & $20,96 \mathrm{~A}$ & 0,05 & $23,23 a$ & 20,97a & 0,060 \\
\hline $\mathrm{RB}(\%)$ & $51,71 \mathrm{~A}$ & $53,05 \mathrm{~A}$ & $53,48 \mathrm{~A}$ & 0,71 & $50,04 b$ & $55,46 a$ & 0,004 \\
\hline RC (\%) & $42,63 \mathrm{~A}$ & $40,48 \mathrm{~A}$ & $41,25 \mathrm{~A}$ & 0,18 & $38,99 b$ & $43,92 \mathrm{a}$ & $<0,0001$ \\
\hline RV (\%) & $43,91 \mathrm{~A}$ & $42,66 \mathrm{~A}$ & $42,83 \mathrm{~A}$ & 0,60 & $40,56 b$ & $45,71 \mathrm{a}$ & $<0,0001$ \\
\hline PPR (kg) & $2,951 \mathrm{~A}$ & 4,632A & $3,755 \mathrm{~A}$ & 0,25 & $3,871 \mathrm{a}$ & 3,687a & 0,823 \\
\hline
\end{tabular}

*PVA = Peso vivo ao abate; PCQ = Peso da carcaça quente; PCF = Peso da carcaça fria; PCV = Peso corporal vazio; $\mathrm{RB}=$ Rendimento biológico; $\mathrm{RC}=$ Rendimento comercial; $\mathrm{RV}=$ Rendimento verdadeiro; $\mathrm{PPR}=$ Perda por resfriamento; **Letras diferentes, maiúsculas para tipos de suplementação e minúsculas para espécies, na mesma linha, significam diferenças estatísticas entre os tratamentos pelo teste de Tukey a 5\% de probabilidade.

O PCF para os animais suplementados com BMs e BMs + buffel foi 10,43 e $10,58 \mathrm{~kg}$, respectivamente. Mesmo sendo inferiores aos dos animais suplementados com sal mineral, esses valores podem ser comparados aos resultados de Bezerra et al. (2012), em estudo com caprinos de $15 \mathrm{~kg}$, em pastejo na caatinga, suplementados, $1 \%$ do peso do animal, com $50 \%$ de palma forrageira e $50 \%$ de farinha de soja, que encontraram PCF de 9,20kg; e aos de Carvalho Júnior et al. (2009), em trabalho com caprinos mestiços F1 Boer x SRD de 15,52kg terminados em pastejo na caatinga, suplementados com $1,5 \%$ de PV, quando observaram PCF de 11,70kg. Essas similaridades indicam que o uso dos BMs pode ser equiparado com suplementações convencionais em pastejo na caatinga.

Quanto às espécies animais, o PCQ, PCF, PCV e $\mathrm{PPR}$ não foram afetados $(\mathrm{P}>0,05)$; tal semelhança nos pesos da carcaça é um fato pouco comum de ocorrer, haja vista que normalmente o peso de ovinos, quando submetidos às mesmas condições, é em geral maior que o de caprinos, como os resultados obtidos neste e em outros trabalhos (Sousa et al., 2009). A não observação dessas diferenças entre ovinos e caprinos neste trabalho pode ser em decorrência de ambas as espécies se adaptarem às suas preferências alimentares por estação do ano e disponibilidade da composição botânica (Osoro et al., 2013).

Os ovinos obtiveram maior peso vivo ao abate (PVA), com média de 27,62kg; mesmo assim os resultados dos caprinos $(25,34 \mathrm{~kg})$ superaram o encontrado por Bezerra et al. (2012), em estudo com cabritos SRD de 90 dias de idade, em pastejo na caatinga, suplementados com palma forrageira e soja, que encontraram PVA de $22,74 \mathrm{~kg}$, ressaltando o bom resultado da suplementação com BMs na caatinga.

Geralmente animais com peso vivo ao abate maior alcançam maiores pesos de carcaças e maior rendimento das mesmas. No entanto, mesmo obtendo maior PVA, os ovinos obtiveram rendimentos (RB, RC e RV) inferiores comparados aos caprinos; isso pode estar relacionado ao maior peso do TGIc dos ovinos (Tab. 5), que refletiu em menor rendimento da carcaça, fato observado também por Sen et al. (2004) em trabalho com ovinos e caprinos.

Quanto aos não constituintes de carcaça comestíveis (g), não houve diferenças estatísticas entre os tipos de suplementação, com exceção do peso do sangue e do fígado $(\mathrm{P}<0,05)$. Já em termos de \%, em relação ao PCV, houve diferenças estatísticas para o TGIv, fígado, coração e rins (Tab. 5).

Similaridade do TGIc (g) entre as suplementações indica semelhança da oferta de forragem nas áreas de caatinga e entre os tipos de suplementações, porém esperava-se que as suplementações com BMs obtivessem menor conteúdo gastrintestinal, por serem compostos de concentrados, já que esse tipo de alimento permanece menos tempo no rúmen, promovendo menor enchimento do TGI (Agricultural..., 
1980). Entretanto a proporção do TGIc dos animais suplementados com BMs + feno de buffel foi maior que a dos suplementados com sal mineral, possivelmente pela presença de mais fibra fornecida pelo feno de buffel, pois, de acordo com Warmington e Kirton (1990), o aumento do teor de fibra da dieta eleva o tempo de retenção do alimento no trato digestório, resultando em um trato gastrintestinal mais pesado.

Tabela 5. Não constituintes da carcaça (parte comestível) em g e em \% de ovinos e caprinos suplementados com blocos multinutricionais em pastejo na caatinga (Caat)

\begin{tabular}{|c|c|c|c|c|c|c|c|}
\hline \multirow[b]{2}{*}{ Variáveis* } & \multicolumn{3}{|c|}{ Tipos de suplementação } & \multirow[b]{2}{*}{$\mathrm{P}^{* *}$} & \multicolumn{2}{|c|}{ Espécies } & \multirow[b]{2}{*}{$\mathrm{P}$} \\
\hline & $\begin{array}{c}\text { Caat + Sal } \\
\text { mineral }\end{array}$ & $\begin{array}{l}\text { Caat + } \\
\text { BMs }\end{array}$ & $\begin{array}{l}\text { Caat + BMs + } \\
\text { feno de Buffel }\end{array}$ & & Ovinos & Caprinos & \\
\hline TGIc & $7123,2 \mathrm{~A}$ & $7474,6 \mathrm{~A}$ & $7548,3 \mathrm{~A}$ & 0,372 & $8206,4 a$ & $6557,6 b$ & $<0,0001$ \\
\hline$\%$ & $32,04 \mathrm{~B}$ & $37,13 \mathrm{AB}$ & $38,60 \mathrm{~A}$ & 0,018 & $39,91 a$ & $31,93 b$ & 0,0001 \\
\hline TGIV & $2014,5 \mathrm{~A}$ & $2075,6 \mathrm{~A}$ & $2020,7 \mathrm{~A}$ & 0,764 & $2055,6 a$ & 2018,3a & 0,61 \\
\hline$\%$ & $8,93 \mathrm{~B}$ & $10,27 \mathrm{~A}$ & $10,12 \mathrm{~A}$ & 0,003 & $9,76 a$ & $9,79 a$ & 0,93 \\
\hline Sangue & $1020,9 \mathrm{~A}$ & $899,45 B$ & $950,15 \mathrm{AB}$ & 0,037 & $958,6 a$ & $955,0 \mathrm{a}$ & 0,92 \\
\hline$\%$ & $4,51 \mathrm{~A}$ & $4,42 \mathrm{~A}$ & $4,75 \mathrm{~A}$ & 0,127 & $4,51 \mathrm{a}$ & $4,60 \mathrm{a}$ & 0,49 \\
\hline Fígado & $446,1 \mathrm{~B}$ & $450,2 B$ & 496,7A & 0,009 & $469,3 a$ & $459,3 a$ & 0,49 \\
\hline$\%$ & $1,98 \mathrm{C}$ & $2,22 \mathrm{~B}$ & $2,49 \mathrm{~A}$ & $<0,0001$ & $2,24 a$ & $2,22 \mathrm{a}$ & 0,80 \\
\hline Coração & $132,4 \mathrm{~A}$ & $134,3 \mathrm{~A}$ & $129,7 \mathrm{~A}$ & 0,720 & $134,8 a$ & $129,4 a$ & 0,25 \\
\hline$\%$ & $0,58 \mathrm{~B}$ & $0,67 \mathrm{~A}$ & $0,65 \mathrm{AB}$ & 0,03 & $0,64 \mathrm{a}$ & $0,62 \mathrm{a}$ & 0,60 \\
\hline Baço & $38,80 \mathrm{~A}$ & $34,70 \mathrm{~A}$ & $39,90 \mathrm{~A}$ & 0,18 & $37,53 a$ & $38,06 a$ & 0,82 \\
\hline$\%$ & $0,17 \mathrm{~A}$ & $0,17 \mathrm{~A}$ & $0,19 \mathrm{~A}$ & 0,09 & $0,17 a$ & $0,18 a$ & 0,66 \\
\hline Diafragma & $58,70 \mathrm{~A}$ & $53,00 \mathrm{~A}$ & $50,30 \mathrm{~A}$ & 0,14 & $55,80 a$ & $52,20 \mathrm{a}$ & 0,30 \\
\hline$\%$ & $0,25 \mathrm{~A}$ & $0,26 \mathrm{~A}$ & $0,25 \mathrm{~A}$ & 0,89 & $0,26 a$ & $0,25 a$ & 0,47 \\
\hline Rins & $86,60 \mathrm{~A}$ & $76,80 \mathrm{~A}$ & $86,30 A$ & 0,03 & $81,66 a$ & $84,80 a$ & 0,35 \\
\hline$\%$ & $0,38 \mathrm{AB}$ & $0,37 \mathrm{~B}$ & $0,43 \mathrm{~A}$ & 0,02 & $0,38 a$ & $0,41 \mathrm{a}$ & 0,15 \\
\hline
\end{tabular}

*TGIc = Trato gastrintestinal cheio; TGIv $=$ Trato gastrintestinal vazio. **Letras diferentes, maiúsculas para tipos de suplementação e minúsculas para espécies, na mesma linha, significam diferenças estatísticas entre os tratamentos pelo teste Tukey a $5 \%$ de probabilidade.

A proporção do TGIv dos animais suplementados com BMs + feno de buffel foi maior que dos suplementados com sal mineral. Isso pode ser explicado pelo fato de esses animais terem consumido mais BMs e assim mais concentrado, o que normalmente promove aumento de comprimento e, consequentemente, de peso dessas vísceras, como forma de ampliar a área de digestão e absorção de nutrientes (Fontenele et al., 2010).

$\mathrm{O}$ peso do sangue foi superior nos animais suplementados com sal mineral, seguido dos suplementados com BMs + feno de buffel. No entanto, quando observado em \%, não se observam diferenças entre as suplementações. $\mathrm{O}$ peso do fígado se mostrou mais elevado nos animais suplementados com BMs + feno de buffel. Provavelmente a ingestão do feno, contido de alto teor de FDN (39,7g/kg) (Tab. 2), tenha elevado o metabolismo dos animais, aumentando assim o tamanho do fígado (Bezerra et al., 2010).
Quanto às espécies, houve diferenças no TGIc (g e \%) (Tab. 5), com maior média observada para a espécie ovina, o que certamente refletiu em maior PVA nessa espécie, tendo assim contribuído para o maior rendimento de carcaça dos caprinos (Tab. 4). Sen et al. (2004), em estudo com caprinos e ovinos em condições semiáridas, encontraram peso de TGI, em relação ao peso vivo, maior nos caprinos em relação aos ovinos. Esses resultados contraditórios entre ovinos e caprinos nos trabalhos geralmente ocorrem em função dos distintos alimentos, além de diferentes períodos de jejum adotados pelos autores (Ribeiro et al., 2012).

Os rins (\%) sofreram efeito da interação $(\mathrm{P}<0,05)$; observando-se que os ovinos suplementados com sal mineral obtiveram rins com menor proporção que nos ovinos suplementados com BMs; já nos caprinos não houve efeito (Tab. 6). 
Tabela 6. Desdobramento da interação para TGIc e rins (\% do PCV) de ovinos e caprinos suplementados com blocos multinutricionais em pastejo na caatinga (Caat)

\begin{tabular}{|c|c|c|c|c|}
\hline \multirow[b]{2}{*}{ Espécies } & \multicolumn{3}{|c|}{ Tipos de suplementação } & \multirow[b]{2}{*}{$\mathrm{P} * *$} \\
\hline & Caat + sal mineral & Caat + BMs & $\begin{array}{c}\text { Caat + BMs + feno } \\
\text { de Buffel }\end{array}$ & \\
\hline \multicolumn{5}{|c|}{ TGIC* \% } \\
\hline Ovinos & $33,44 \mathrm{Ba}$ & 40,40Aa & 45,88Aа & \\
\hline Caprinos & 30,63Aa & 33,85Aa & $31,32 \mathrm{Ab}$ & 0,04 \\
\hline \multicolumn{5}{|c|}{ Rins\% } \\
\hline Ovinos & $0,37 \mathrm{Aa}$ & $0,33 \mathrm{Bb}$ & $0,45 \mathrm{Aa}$ & \\
\hline Caprinos & 0,39 Aа & $0,42 \mathrm{Aa}$ & $0,41 \mathrm{Aa}$ & 0,01 \\
\hline
\end{tabular}

*TGIc = Trato gastrintestinal cheio. ${ }^{* *}$ Letras maiúsculas diferentes na mesma linha indicam que houve diferenças significativas entre os tipos de suplementação, e letras minúsculas diferentes na coluna indicam diferenças significativas entre as espécies pelo teste de Tukey a 5\% de probabilidade.

Os ovinos suplementados com BMs + feno de buffel obtiveram maior percentual de TGIc (45,88\%) que os caprinos (31,32\%). Provavelmente, isso se deve à presença do feno de buffel neste tratamento, em que os ovinos, sendo animais pastejadores ou selecionadores de alimentos volumosos, consomem mais feno que os caprinos, ramoneadores, ocasionando maior tempo desse volumoso no trato gastrintestinal dos ovinos, fato também reportado por Moreno et al. (2011). Essa tendência não foi observada nos caprinos; possivelmente pelo hábito dos ovinos em consumir mais gramíneas do que os caprinos. Essa observação é reforçada pela diferença significativa observada entre as espécies, ao se verificar superioridade dos ovinos quanto ao TGIc apenas quando suplementados com BMs + feno de buffel.

\section{CONCLUSÕES}

A suplementação com blocos multinutricionais (BMs), acrescidos ou não de feno de baixa qualidade, de ovinos e caprinos sob pastejo direto da caatinga, na época chuvosa do Curimataú paraibano, com quantidade e qualidade de forragem, não resulta em ganhos produtivos significativos.

\section{REFERÊNCIAS}

AGRICULTURAL Research Council - ARC. The nutrient requirements of ruminants livestock. London: Common wealth agricultural, Bureaux, 1980. 351p.

ANDRADE, A.P.; COSTA, R.G.; SANTOS, E.M.; SILVA, D.S. Produção animal no semiárido: o desafio de disponibilizar forragem, em quantidade e com qualidade, na estação seca. Rev. Tecnol. Ciên. Agropec., v.4, p.1-14, 2010.
ARAÚJO FILHO, J.A.; VALE, L.V.; ARAUJO NETO, R.B. Dimensões de parcelas para amostragem do estrato herbáceo da Caatinga raleada. In: REUNIAO ANUAL DA SOCIEDADE BRASILEIRA DE ZOOTECNIA. 23., 1987, Campo Grande, Anais... Campo Grande: [s.n.] 1987. p.268. (Resumo).

ARAUJO-FEBRES, O.; GADEA, J.; ROMERO, M. et al. Efecto de la dureza de los bloques multinutricionales sobre el consumo voluntario en bovinos mestizos. Arch. Lat. Amer. Prod. Ani., v.40, p.217-219, 1997.

ATTI, N.; BEN SALEM, H. Compensatory growth and carcass composition of Barbarine lambs receiving different levels of feeding with partial replacement of the concentrate with feed blocks. Anim. feed sci. technol., v.147, p.265-277, 2008.

BEN SALEM, H. Nutritional management to improve sheep and goat performances in semiarid regions. Rev. Bras. Zootec., v.39, p.337-347, 2010 (supl. especial).

BEN SALEM, H.; NEFZAOUI, A. Feed blocks as alternative supplements for sheep and goats. Small. Rumin. Res., v.49, p.275-288, 2003.

BEZERRA, S.B.L; VERAS, A.S.C; SILVA, D.K.A. et al. Componentes não integrantes da carcaça de cabritos alimentados em pastejo na Caatinga. Pesq. agropec. bras., v.45, p.751-757, 2010.

BEZERRA, S.B.L.; VÉRAS, A.S.C.; SILVA, D.K.A. et al. Morphometry and carcass characteristics of goats submitted to grazing in the Caatinga. Rev. Bras. Zootec., v.41, p.131-137, 2012.

CARVALHO JÚNIOR, A.M.; PEREIRA FILHO, J.M.; SILVA, R.M. et al. Efeito da suplementação nas características de carcaça e dos componentes nãocarcaça de caprinos F1 Boer $\times$ SRD terminados em pastagem nativa. Rev. Bras. Zootec., v.38, p.13011308, 2009. 
CEZAR, M.F.; SOUSA, W.H. Carcaças ovinas e caprinas: obtenção-avaliação-classificação. 1.ed. Uberaba: Agropecuária Tropical, 2007. 232p.

EMEPA. Empresa Estadual de Pesquisa agropecuária da Paraíba S/A. EMEPA - Estação Experimental de Pesquisa, 2012. Disponível em: < http://www.emepa.org.br/empresa/ee/eexp_pendencia. pdf $>$ Acessado em: 25 jan. 2013.

FONTENELE, R.M.; PEREIRA, E.S.; PIMENTEL, P.G. et al. Níveis de energia metabolizável em rações de ovinos Santa Inês: peso dos órgãos internos e do trato digestório. Semina Cienc. Agrar., v.31, p.10951104, 2010.

GONZAGA NETO, S.; BATISTA, A.M.V.; CARVALHO, F.F.R. et al. Composição bromatológica, consumo e digestibilidade In Vivo de dietas com diferentes níveis de feno de catingueira (Caesalpineabracteosa), fornecidas para ovinos Morada Nova. Rev. Bras. Zootec., v.30, p.553-562, 2001.

KAWAS, J.R.; ANDRADE-MONTEMAYOR, H.; LU, C.D. Strategic nutrient supplementation of freeranging goats. Small. Rumin. Res., v.89, p.234-243, 2010.

MAKKAR, H.P.S.; SÁNCHEZ, M.; SPEEDY, A.W. Feed supplementation blocks. Urea-molasses multinutrient blocks: simple and effective feed supplement technology for ruminant agriculture. (Ed) FAO/IAEA Division of Nuclear Techniques in Food and Agriculture and Animal Production and Health Division, FAO, 2007. 252p.

MARTÍNEZ-MARTÍNEZ, R.; LÓPEZ-ORTIZ, S.; ORTEGA-CERRILLA, M.E. et al. Preference, consumption and weight gain of sheep supplemented with multinutritional blocks made with fodder tree leaves. Livest. sci., v.149, p.185-189, 2012.

MORENO, G.M.B.; SILVA SOBRINHO, A.G.; LEÃO, A.G. et al. Rendimento dos componentes nãocarcaça de cordeiros alimentados com silagem de milho ou cana-de-açúcar e dois níveis de concentrado. Rev. Bras. Zootec., v.40, p.2878-2885, 2011.

OLIVEIRA, A.N.; SELAIVE-VILLARROEL, A.B.; MONTE, A.L.S. et al. Características da carcaça de caprinos mestiços Anglo-Nubiano, Boer e sem padrão racial definido. Cienc. Rural., v.38, p.1073-1077, 2008.
OSORO, K.; FERREIRA, L.M.M.; GARCÍA, U. et al. Diet selection and performance of sheep and goats grazing on different heathland vegetation types. Small. Rumin. Res., v.109, p.119-127, 2013.

PEREIRA FILHO, J.M.; BAKKE, O.A. Produção de forragem de espécies herbáceas da caatinga. IN: USO SUSTENTÁVEL E CONSERVAÇÃO DOS RECURSOS FLORESTAIS DA CAATINGA. (Ed). Serviço Florestal Brasileiro, Brasília: 2010. 368p.

PROHMANN, P.E.F.; BRANCO, A.F.; JOBIM, C.C. et al. Suplementação de Bovinos em Pastagem de Coastcross (Cynodondactylon (L.) Pers) no Verão. Rev. Bras. Zootec., v.33, p.792-800, 2004.

RIBEIRO, T.M.D.; COSTA, C.; MONTEIRO, A.L.G. et al. Carcaças e componentes não-carcaça de cordeiros terminados em pasto de azevém recebendo suplementação concentrada. Cienc. Rural., v.42, p.526-531, 2012.

SEN, A.R.; SANTRA, A.; KARIM, S.A. Carcass yield, composition and meat quality attributes of sheep and goat under semiarid conditions. Meat Science., v.66, p.757-763, 2004.

SILVA, D.J.; QUEIROZ, A.C. Análises de alimentos (Métodos químicos e biológicos). 3.ed. Viçosa: Editora UFV, 2002. 235p.

SOUSA, W.H.; BRITO, E.A.; MEDEIROS, A.N. et al. Características morfométricas e de carcaça de cabritos e cordeiros terminados em confinamento. Rev. Bras. Zootec., v.38, p.1340-1346, 2009.

STATISTICAL analisys system. SAS user's guide: statistics. Versão 9.1. (Ed): Cary: SAS, 2003.

VAN SOEST, P.J. Nutritional ecology of the ruminant. 2. ed. Ithaca: Cornell University Press, 1994. 476p.

WARMINGTON, B.G.; KIRTON, A.H. Genetic and non-genetic influences on growth and carcass traits of goats. Small. Rumin. Res., v.3, p.147-165, 1990.

YDOYAGA-SANTANA, D.F.Y.; LIRA, M.A.; SANTOS, M.V.F. et al. Caracterização da caatinga e da dieta de novilhos fistulados, na época chuvosa, no semiárido de Pernambuco. Rev. Bras. Zootec., v.40, p.69-78, 2011. 